\title{
CARACTERIZAÇÃO FENOTÍPICA DE TRÊS SELEÇÕES DE MARACUJAZEIRO-ROXO (Passiflora edulis Sims) ${ }^{1}$
}

\author{
LAURA MARIA MOLINA MELETTI², MARTA DIAS SOARES-SCOTT², LUÍS CARLOS BERNACCI²
}

\begin{abstract}
RESUMO - O interesse pelo cultivo do maracujazeiro-roxo vem crescendo no centro-sul do País, visando à exportação. Observa-se um número significativo de formas selvagens, nativas, compatíveis entre si, propagadas por sementes de polinização aberta, ampliando a variabilidade natural da fruteira. Com o objetivo de identificar cruzamentos com características comerciais desejáveis e disponibilizar sementes de matrizes selecionadas aos produtores, foram realizados estudos de caracterização agronômica, morfológica e citogenética, envolvendo seleções do Banco de Germoplasma de Passifloras do IAC, denominadas 'Roxinho-Miúdo', 'Paulista' e 'Maracujá-Maçã'. Durante duas safras consecutivas, foram analisados cerca de 350 flores e 150 frutos de cada seleção. A maior amplitude de variação ocorreu na massa e no tamanho dos frutos (de 21 a 193 g por fruto), seguidos pelo teor de sólidos solúveis (de 15,2 a 21,4 ${ }^{\circ}$ Brix), produção por planta (11,5 a 30,8 kg) e número de sementes por fruto (de 39 a 261 sementes). A viabilidade polínica variou de 77 a $94,5 \%$, enquanto o teste de germinação do pólen em ágar apresentou índices de 65,5 a $86 \%$, contribuindo para o diferencial em produtividade observado. Todas as seleções apresentaram características comerciais desejáveis. 'Roxinho-Miúdo' possui fruto redondo, pequeno, com $4 \mathrm{~cm}$ de diâmetro, doce e de coloração roxo-intensa, adequando-se à preferência internacional. A seleção 'Paulista' apresentou frutos ovais, destacando-se pela dupla finalidade, podendo atender também à agroindústria. O 'Maracujá-Maçã' distinguiu-se pelo maior tamanho, formato arredondado e casca rosada, apto para um segmento diferenciado de mercado, que comercializa frutas por unidade e privilegia a qualidade. Termos para indexação: maracujá-roxo, Passiflora edulis, variabilidade, caracterização.
\end{abstract}

\section{PHENOTYPIC CHARACTERIZATION IN THREE SELECTIONS OF PURPLE PASSION FRUIT (Passiflora edulis Sims)}

\begin{abstract}
The interest in purple passion-fruit production is becoming higher in southeast of Brazil, aiming exportation. There are some wild, different native types with high variability due open pollination that promotes an increase in natural variability. The aim of the present work is to identify varieties with commercial values among the species and the production of seeds for breeders wishing the selection for yield improvement. In the present paper were studied horticultural, cytogenetic and morphological characters among genotypes from the IAC Germoplasm Bank of Passiflora ('Roxinho-miúdo', 'Paulista' and 'Maracujá-Maçã'). It was analyzed in each material three hundred and fifty flowers and one hundred and fifty fruits during two consecutive years. Higher differences were observed in fruit weight and size (21 to $193 \mathrm{~g}$ per fruit), TSS (15.2 to $21.4^{\circ}$ Brix), plant production ( 11.5 to $30.8 \mathrm{~kg}$ ) and number of seeds in the fruit (39 to 261 seeds). The pollen fertility rises from seventy-seven until ninety four percent and pollen germination was higher increasing the fruit productivity. The tested selections presented desirable commercial characteristics. The "Roxinho Miúdo" has a round small fruit, with a $4 \mathrm{~cm}$ diameter, sweet, purple dark, excellent to an international consumer. The 'Paulista' has oval fruits and good to fresh fruit market and or to juicy industry. The 'Maracujá-Maçã' has the biggest size; a round and a pinky colored peel good to be traded in a unique market that commercializes fruits by unit and privileges the quality. Index terms: purple passion fruit, Passiflora edulis, variability, and characterization.
\end{abstract}

\section{INTRODUÇÃO}

O gênero Passiflora reúne cerca de 400 espécies de maracujá, a maioria originária da região Neotropical (América), sendo cerca de 120 nativas do Brasil (Bernacci et al., 2003). Há, portanto, ampla variabilidade genética a ser conhecida e convenientemente manuseada. Apesar disso, os cultivos comerciais do País baseiam-se numa única espécie, o maracujá-amarelo ou azedo. Ela representa $95 \%$ dos pomares, devido à qualidade dos seus frutos, vigor, produtividade e rendimento em suco (Meletti \& Brückner, 2001). Em 1999, foram cultivados cerca de 35.000 ha com essa fruteira (FNP, 2001), o que faz do País o maior produtor mundial.

Em menor escala, com importância bastante regionalizada e comercialização restrita, são cultivados o maracujá-doce (Passiflora alata), o maracujá-roxo (P. edulis), o maracujá-melão (P. quadrangularis), o maracujá-suspiro ( $P$. nitida) e o maracujá-tubarão $(P$. cincinnata $)$, confundido com o maracujá-de-flor-azul ( $P$. caerulea), conforme apontam Inglez de Souza \& Meletti (1997).

Na maioria dos países produtores, o maracujá-amarelo é o mais importante. Mas na África do Sul, Quênia, Estados Unidos e Nova Zelândia, há extensos pomares de maracujá-roxo. Na Austrália, cultivamse principalmente híbridos de maracujá-roxo e maracujá-amarelo, de casca roxa ou rosada (Meletti \& Brückner, 2001). O mercado internacional é bastante receptivo ao maracujá-roxo, daí o interesse na produção da fruta in natura.

Para viabilizar a produção em larga escala e eventual exportação do maracujá-roxo, faz-se necessária a ampliação dos pomares, a fim de garantir regularidade de oferta. Para tanto, é preciso, inicialmente, identificar genótipos superiores ou seleções regionais que atendam aos interesses do mercado. O presente trabalho visa a caracterizar três seleções de maracujazeiro-roxo do BAG-IAC e apontar os mais promissores para a diversificação dos pomares nacionais.

\section{MATERIALE MÉTODOS}

O Instituto Agronômico mantém um Banco Ativo de Germoplasma de Passifloras, freqüentemente ampliado por meio de coletas, introduções ou recombinações entre os acessos. Da caracterização deste BAG, foram identificados acessos promissores (Meletti et al., 1992; Meletti et al., 1994), cujos descendentes foram cultivados como seleções, e analisados quanto às suas características agronômicas, morfológicas e citogenéticas.

Foram caracterizadas três seleções: 'Maracujá-Maçã', 'Paulista' e 'Roxinho-Miúdo'. A primeira resultou da hibridação entre um acesso de maracujá-amarelo proveniente de Catiguá-SP e outro de maracujároxo proveniente da UNESP-Jaboticabal, denominada 'Córrego Rico' por Oliveira et al. (1987), sendo, portanto, uma população segregante do híbrido intra-específico ( $P$. edulis) de casca rosada. A seleção 'Maracujá-maçã' representa, atualmente, uma variedade comercial lançada no mercado em 1999, descrita por Meletti (2000).

'Paulista' foi obtida pela recombinação entre dois acessos de casca roxa coletados em pomares de Garça e Pindorama-SP, enquanto a

\footnotetext{
${ }^{1}$ (Trabalho 145/2004). Recebido: 04/11/2004. Aceito para publicação: 07/07/2005. Trabalho parcialmente apresentado no II Simpósio Brasileiro de Melhoramento de Fruteiras, Viçosa-MG, 2000. Apoio: FUNDAG.

${ }^{2}$ Pesquisadores Científicos, Instituto Agronômico, IAC. Caixa Postal 28, Campinas-SP. CEP: 13.001-970. E-mail: 1mmm@iac.sp.gov.br.
} 
seleção 'Roxinho-Miúdo' foi obtida a partir do cruzamento entre um acesso proveniente da UNESP-Jaboticabal e outro coletado em estado selvagem, em Jundiaí-SP, ambos com frutos miúdos e quase roxos.

Materiais-testemunha das três seleções encontram-se depositados no herbário IAC, do Instituto Agronômico, em Campinas, estando registrados sob os números 37119, 44017, 44021, 45033 e 45339 ('Paulista'), 44013, 44015, 44020 e 45340 ('Maracujá-Maçã) e 45094 e 45095 ('Roxinho-Miúdo'), sendo que as informações de coleta das amostras estão disponíveis on-line.

Foram avaliadas plantas com cerca de 2 anos de idade, formadas a partir das sementes dos cruzamentos controlados, conduzidas em espaldeira com um fio de arame, sem irrigação. Os tratos culturais adotados seguiram as recomendações técnicas para a cultura no Estado de São Paulo, prescritas por Meletti \& Maia (1999).

Foram considerados os dados obtidos no período de 19931995, resultantes da avaliação por duas safras consecutivas. As plantas estavam distribuídas em blocos ao acaso, com 3 repetições e 3 plantas por parcela.

Para a caracterização agronômica, inicialmente foi observado o número médio de flores por planta, em picos de florescimento. Em seguida, foram analisados 150 frutos por seleção, colhidos na máxima maturação fisiológica. Cerca de $20 \%$ deles foram colhidos ainda presos à planta-mãe, mas sempre depois de obtida a coloração roxa da casca, por insolação natural. As determinações de diâmetro equatorial $(\varnothing \mathrm{E}) \mathrm{e}$ longitudinal $(\varnothing \mathrm{L})$ dos frutos e espessura do mesocarpo (EM) foram feitas por leitura direta em cada amostra, com paquímetro manual, em centímetros. Pela relação entre os dois diâmetros, foi obtido o índice de formato dos frutos (IF), que define frutos tanto mais redondos quanto mais o IF se aproxima de 1,0. A massa dos frutos (m) foi obtida individualmente, numa balança fixa com $15 \mathrm{~kg}$ de capacidade e sensibilidade de $1 \mathrm{~g}$. O teor de sólidos solúveis totais - SST ( $\left.{ }^{\circ} \mathrm{Brix}\right)$ foi determinado por leitura direta em refratômetro manual, com os dados corrigidos pela temperatura. O número de sementes (NS) foi contado fruto a fruto. Foi feita, ainda, a determinação do rendimento em suco $(\%)$, pela relação entre o volume de suco e o peso do fruto, e a determinação da produção de cada planta (kg/planta/ano).

Os dados agronômicos foram submetidos à análise de variância, empregando-se o teste F, com as médias comparadas pelo Teste de Tukey, ao nível de $5 \%$ de probabilidade.

$\mathrm{Na}$ análise citogenética, foram observados a morfologia dos cromossomos mitóticos e comportamento meiótico na gametogênese. A técnica utilizada para a obtenção de metáfases mitóticas foi de Squash (esmagamento) em pontas de radículas, pré-tratadas com 8 hidroxiquinolina por 3 horas, à temperatura ambiente, fixadas em etanol acético $(3: 1)$, mantidas a $7^{\circ} \mathrm{C}$. As lâminas foram coradas com solução Giemsa/Sorensen pH 6,8 (coloração normal). O cariótipo foi montado a partir de 10 metáfases mitóticas, que foram fotografadas e medidas, para obter o comprimento absoluto $(\mu \mathrm{m})$, o comprimento relativo (\%), a razão de braços (comprimento do braço longo/comprimento do braço curto), calculados segundo Levan et al. (1964) e Guerra (1988). Para a análise da microsporogênese, botões florais de diversos tamanhos foram coletados em diferentes épocas do ano, analisando-se diversas fases da meiose, utilizando o esmagamento de anteras (Medina \& Conagin 1964; Darlington \& La Cour 1977).

Para a determinação da capacidade de reprodução, foram realizados testes de viabilidade polínica, segundo Alexander (1980), e teste de germinação de pólen, segundo Broglia \& Brunori (1994), e técnicas adaptadas (Soares-Scott, 1998). Ambos os testes utilizam pólen fresco coletado na antese das flores. A viabilidade polínica foi feita em lâminas, utilizando corante com ácido lático, sendo a viabilidade detectada por diferença de cor. Foram avaliados 10 flores e 300 pólens por flor, em cada seleção.

Para a caracterização morfológica, foram considerados: diâmetro do ramo, comprimento e largura da lâmina foliar, e dos lobos central e laterais, da estípula, dos nectários do pecíolo, e comprimento do pecíolo e da porção unida da lâmina foliar, analisados através do teste de quartis ("box plots"), segundo McGill et al. (1978).

\section{RESULTADOS E DISCUSSÃO}

$\mathrm{Na}$ caracterização citogenética, não foram observadas diferenças cromossômicas entre os acessos, possivelmente por serem todos da mesma espécie. O número cromossômico de Passiflora edulis é de $2 \mathrm{n}=18$. O cariótipo (Tabela1) mostrou sete pares de cromossomos metacêntricos $(1 ; 2 ; 3 ; 5 ; 6 ; 8$ e 9$)$ e dois pares de submetacêntricos (4 e 7 ), sendo sua fórmula cariotípica $7 \mathrm{M}+2 \mathrm{SM}$, indicando simetria cariotípica (Soares-Scott, 1998).

O comprimento haplóide do genoma foi de 21,59 $\pm 0,57 \mu \mathrm{m}$, próximo ao observado em outras espécies do gênero, sendo os cromossomos maiores os de número 4 , com centrômero na região submediana e o de número 1 , com centrômero na posição mediana, e os menores, os de número 8 e 9, metacêntricos, conforme Tabela 1. Os pares de cromossomos 4 e 7 possuem constrição secundária no braço longo (Soares-Scott, 1998).

Pela análise das diferentes fases da meiose, observou-se que esta se mostrou regular nas três seleções. A partir disso, espera-se bons índices de viabilidade polínica (Soares-Scott et al, 2003), confirmado pelas análises de germinação do pólen. As seleções 'Paulista', 'MaracujáMaçã' e 'Roxinho-Miúdo' alcançaram os valores de $86 \%, 78 \%$ e $65,5 \%$, respectivamente, na mesma proporção da produção observada por planta.

Quanto às características morfológicas vegetativas, no geral, o 'Maracujá-Maçã' apresentou os maiores valores e 'Roxinho-Miúdo', os menores, normalmente havendo diferenças significativas apenas em relação ao 'Maracujá-Maçã', tal como em relação à largura foliar (Figura 1a), comprimento foliar e do pecíolo, largura do lobo central e comprimento e largura dos lobos laterais. Não houve diferença significativa entre as três seleções quanto ao comprimento da porção unida da lâmina foliar (Figura 1b) e à largura da estípula e houve diferença significativa entre elas quanto ao comprimento do lobo central (Figura 1c) e dos nectários do pecíolo. 'Roxinho-Miúdo' apresentou ramos

TABELA 1 - Caracterização citogenética de Passiflora edulis. Medidas cromossômicas obtidas numa média de 10 metáfases mitóticas. IAC, Campinas-SP, 1998.

\begin{tabular}{|c|c|c|c|c|c|c|c|}
\hline \multirow{2}{*}{$\frac{\text { Cromossomos }}{1}$} & \multicolumn{2}{|c|}{ Compr.Absoluto $(\mu \mathrm{m})$} & \multicolumn{2}{|c|}{ Compr. Relativo $(\mu \mathrm{m})$} & \multicolumn{2}{|c|}{ Razão de braços } & \multirow{2}{*}{$\begin{array}{r}\text { Tipo } \\
M\end{array}$} \\
\hline & 2,75 & 0,09 & 12,73 & 0,26 & 1,28 & 0,03 & \\
\hline 2 & 2,62 & 0,11 & 12,40 & 0,32 & 1,33 & 0,09 & M \\
\hline 3 & 2,41 & 0,07 & 12,16 & 0,17 & 1,12 & 0,05 & M \\
\hline 4 & 3,15 & 0,13 & 14,55 & 0,61 & 1,67 & 0,06 & SM \\
\hline 5 & 2,22 & 0,08 & 10,41 & 0,27 & 1,25 & 0,08 & M \\
\hline 6 & 2,04 & 0,08 & 9,50 & 0,18 & 1,15 & 0,07 & M \\
\hline 7 & 2,96 & 0,16 & 13,70 & 0,53 & 2,52 & 0,08 & SM \\
\hline 8 & 1,78 & 0,07 & 8,22 & $0 ., 26$ & 1,16 & 0,05 & $\mathrm{M}$ \\
\hline 9 & 1,67 & 0,04 & 7,75 & 0,17 & 1,16 & 0,06 & M \\
\hline
\end{tabular}

Onde: $\mathrm{SM}=$ submetacêntrico; $\mathrm{M}=$ metacêntrico e compr. = comprimento. 

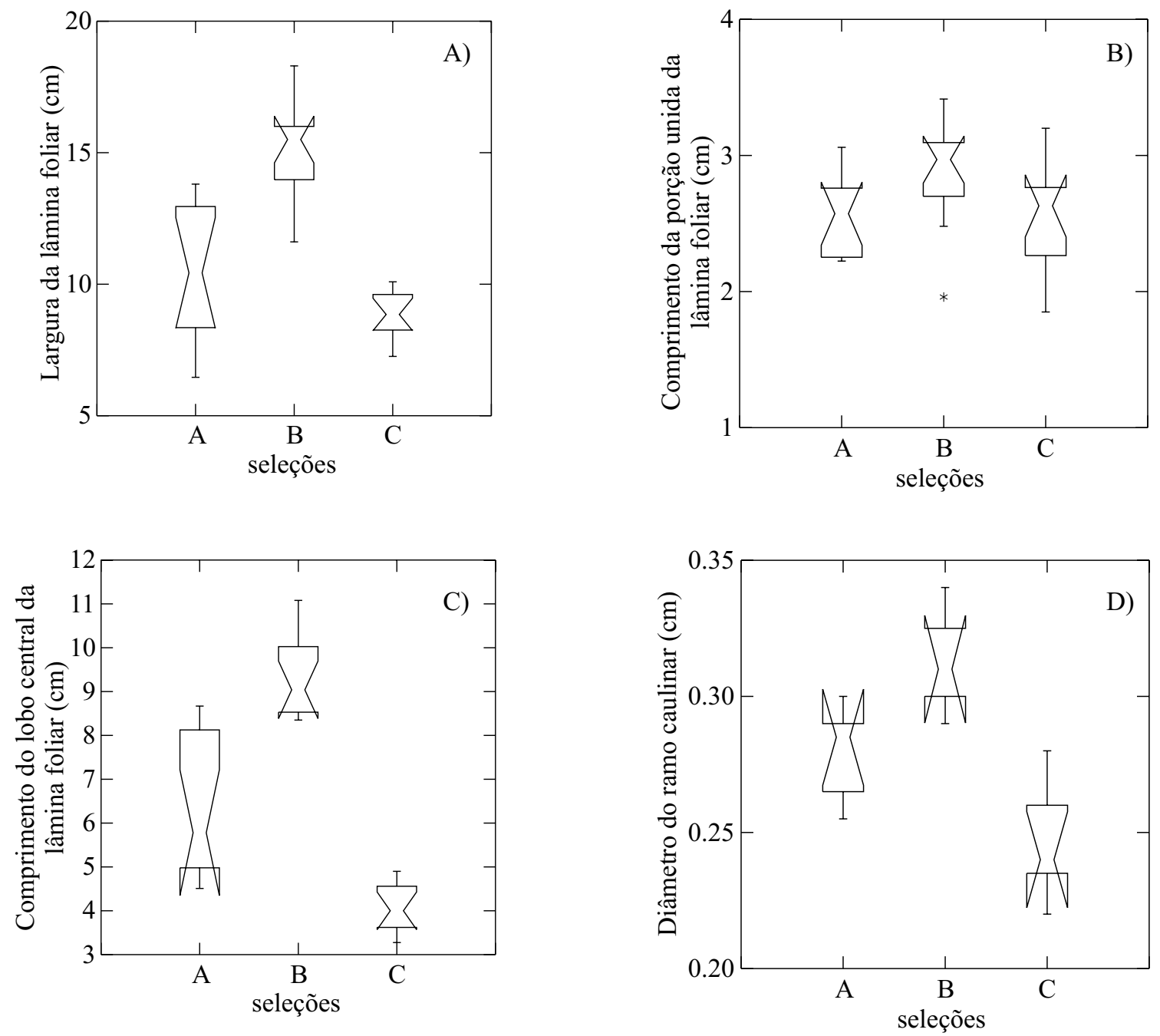

FIGURA 1 - Largura (a), comprimento da porção unida (b) e do lobo central da lâmina foliar (c) e diâmetro do ramo caulinar (d) em três seleções de maracujá-roxo (Passiflora edulis Sims): A 'Paulista'; B 'Maracujá-Maçã' e C 'Roxinho-Miúdo'. As linhas inclinadas (estreitamento no polígono) representam o limite de confiança (e a porção mais estreita a mediana), sendo que, diferenças significativas ocorrem se os estreitamentos dos polígonos não se sobrepõem na escala, entre as seleções consideradas.

TABELA 2 - Médias de características agronômicas e Viabilidade Polínica (VP) de seleções de Maracujazeiro-roxo (Passiflora edulis Sims). Instituto Agronômico, BAG, 1993-1995.

\begin{tabular}{|c|c|c|c|c|c|c|c|c|c|c|}
\hline $\begin{array}{l}\text { BAG-IAC } \\
\text { P. edulis }\end{array}$ & Nflor/plta* & $\begin{array}{c}\text { Produção } \\
\mathrm{Kg} / \text { plta/ano }\end{array}$ & $\begin{array}{l}\text { VP } \\
(\%)\end{array}$ & $\begin{array}{c}\text { massa } \\
(\mathrm{g})\end{array}$ & $\mathrm{L}(\mathrm{cm})$ & $\begin{array}{r}. E \\
(\mathrm{~cm}) \\
\end{array}$ & IF & $\begin{array}{l}\text { EM } \\
(\mathrm{cm})\end{array}$ & $\begin{array}{c}\text { SST } \\
\text { ( Brix) }\end{array}$ & $\begin{array}{c}\text { N S } \\
\text { por fruto }\end{array}$ \\
\hline 'Roxinho-Miúdo' & $25 \mathrm{a}$ & $11,5 \mathrm{c}$ & 77,0 & $21 \mathrm{~b}$ & $4,2 \mathrm{~b}$ & $4,1 \mathrm{~b}$ & 1,02 & $0,3 \mathrm{~b}$ & $21,4 \mathrm{a}$ & $39 \mathrm{~b}$ \\
\hline 'Paulista' & $22 \mathrm{a}$ & $30,8 \mathrm{~b}$ & 94,5 & $193 \mathrm{a}$ & $8,7 \mathrm{a}$ & $6,6 \mathrm{a}$ & 1,32 & $0,7 \mathrm{a}$ & $15,6 \mathrm{~b}$ & $227 \mathrm{a}$ \\
\hline 'Maracujá-Maçã' & $26 \mathrm{a}$ & $29,1 \mathrm{~b}$ & 89,7 & $169 \mathrm{a}$ & $8,9 \mathrm{a}$ & $7,8 \mathrm{a}$ & 1,15 & $0,9 \mathrm{a}$ & $15,2 \mathrm{~b}$ & $261 \mathrm{a}$ \\
\hline
\end{tabular}

Média de dois picos de forescimento. Onde: $\mathbf{V P}(\mathbf{\%})=$ viabilidade polínica; $\varnothing \mathbf{L}=$ diâmetro longitudinal fruto; $\varnothing \mathbf{E}=$ diâmetro equatorial fruto;

$\mathbf{I F}=$ índice de formato dos frutos; $\mathbf{E M} .=$ espessura do mesocarpo; $\mathbf{S S T}=$ teor de sólidos solúveis totais; $\mathrm{N}^{\circ} \mathbf{S}=$ número médio de sementes por fruto.

Médias seguidas pela mesma letra não diferem entre si, pelo Teste de Tukey, ao nível de $5 \%$ de probabilidade.

significativamente mais estreitos (Figura 1d) e 'Paulista', estípulas significativamente mais curtas que 'Maracujá-Maçã'.

Os dados da avaliação agronômica e de viabilidade polínica encontram-se na Tabela 2.

Para número de flores/planta, não houve diferenças significativas entre as três seleções (Tabela 2), considerando dois picos de florescimento. Isso parece demonstrar que as plantas possuem a mesma intensidade de florescimento. No entanto, não se observou igual produção por planta (Tabela 2), em função das particularidades de cada seleção. 'Roxinho-Miúdo' tem frutos menores e mais leves que os demais. Sua viabilidade polínica inferior também deve ser considerada, porque, em cruzamentos controlados, isso reduz a capacidade produtiva da planta. Levando-se em conta esses dois fatores, observou-se menor produção para esta seleção (11,5 kg/planta/ano), enquanto as demais estiveram em torno dos $30 \mathrm{~kg} /$ planta/ano (Tabela 2).

Entretanto, isto não representa uma limitação para seu cultivo, porque, em maracujá-roxo, a qualidade dos frutos é mais importante que a produção quantitativa. Apesar de seus frutos serem diferentes dos demais, pequenos e redondos (Tabela 2), expresso por m, $\varnothing \mathrm{L}$ e $\varnothing \mathrm{T}$ e IF, há que se considerar conjuntamente produção com as demais características. Os dados encontrados para peso e tamanho dos frutos, formato e espessura da casca de 'Roxinho-Miúdo' foram bastante semelhantes aos obtidos por Oliveira et al. (1987) para os acessos 'Silvestre-de-Jundiaí' e 'Roxo Selvagem IAC,' que também apresentaram frutos leves, pequenos, redondos, de casca roxa e polpa amarelocanário. Provavelmente, referem-se a materiais similares, uma vez que a região de coleta é a mesma.

O teor de SST ora obtido na caracterização de 'Roxinho-Miúdo' (Tabela 2) superou significativamente o das outras duas seleções analisadas. Isso é importante para elevar a relação açúcares/acidez e tornar o fruto mais adocicado, e, por isso, mais aceito em países europeus (Souza e Sandi, 2001). Assim, 'Roxinho-Miúdo' adapta-se à preferência internacional. O elevado teor de SST dispensa ainda o uso de açúcar quando consumido (Toda Fruta, 2002). Também pode melhorar as 
características do suco atualmente produzido no Brasil.

Os acessos nacionais com frutos similares a 'Roxinho-Miúdo', citados por Oliveira et al. (1987), e o maracujá-roxo produzido na Espanha, descrito por Souza \& Sandi (2001), registraram teores de SST de 14 a $14,5^{\circ}$ Brix. Como 'Roxinho-Miúdo' apresentou teor de SST $7^{\circ}$ Brix mais elevado, uma diferença bastante considerável, isso poderia demonstrar que a recombinação entre acessos levada a efeito em 'Roxinho-Miúdo' pode resultar em ganhos expressivos nas características desejáveis. Assim, esta seleção poderia ter lugar nas exportações brasileiras, que ainda não se estabeleceu por falta de produto e logística, não por inadequação do produto.

A produção do 'Roxinho-Miúdo' para mercado interno ainda não é feita em larga escala, apesar da sua aceitação. Até o momento, tímidas iniciativas de comercialização de frutos in natura foram observadas, como a venda de caixetas plásticas transparentes, com seis unidades cada. Sua polpa é amarelo-canário, doce, pouco ácida e suculenta, bastante apreciada.

Entre 'Paulista'e 'Maracujá-Maçã', não houve diferença significativa para tamanho e massa dos frutos, espessura de casca, teor de SST e número de sementes. Ambas apresentaram frutos maiores e mais pesados que 'Roxinho-Miúdo' (Tabela 2), superando também o padrão comercial de maracujá-amarelo e de maracujá-roxo descrito por Oliveira et al. (1987), demonstrando suas qualidades comerciais. Elas foram particularmente superiores na massa do fruto $(\mathrm{m})$, que alcançou o dobro da apresentada pelo maracujá-roxo daqueles autores.

Há que se salientar, ainda, que 'Paulista' é oval (apresentou o maior índice de formato), com polpa suculenta, amarelo-alaranjada, semelhante ao padrão de maracujá-amarelo apreciado pelos brasileiros. Além disto, o tamanho, a massa dos frutos e o teor de SST encontrados nesta seleção superam todas as descrições anteriores registradas para maracujá-roxo (Oliveira et al., 1987; Meletti et al., 1994). 'Paulista' mostrou-se superior inclusive a acessos que já foram indicados para cultivo comercial por Oliveira et al. (1987), como ‘Córrego-Rico' e 'Miúdodo-Paraná', devido às suas características agronômicas favoráveis.

Outra vantagem da seleção 'Paulista' é o rendimento em suco. Quando associado ao teor de SST, ambos superam o padrão atualmente adotado na fabricação de sucos, descrito por Souza e Sandi (2001), que é de 30-33\% de rendimento médio e teor de SST mínimo de $11^{\circ}$ Brix, a $20^{\circ}$ C. A seleção 'Paulista' alcançou $40 \%$ de rendimento em suco e $15,6^{\circ}$ Brix de SST.

'Maracujá-Maçã e 'Roxinho-Miúdo' apresentaram 32 e 37\% de rendimento em suco, respectivamente, também superiores aos acessos recomendados por Oliveira et al. (1987). Como essas seleções possuem frutos mais adequados ao mercado de frutas frescas, não seriam, a princípio, cultivadas para a agroindústria. Mas, em função da combinação entre elevado teor de SST e rendimento em suco, poderiam eventualmente ter dupla finalidade.

'Maracujá-Maçã' apresentou frutos mais arredondados, o que não é interessante para a comercialização por atacadistas. Este formato resulta num aumento de volume ocupado sem o proporcional aumento em peso. A embalagem-padrão passa a não atingir o peso determinado para a sua comercialização, o que não ocorre com frutos ovais, que são preferíveis.

O fruto de 'Maracujá-Maçã' apresentou casca mais espessa que a de 'Roxinho-Miúdo' (Tabela 2), uma vantagem adicional no prazo de comercialização de frutas frescas. É, também, um fruto diferenciado em coloração e formato, adequado ao segmento de mercado dos produtos individualizados pela qualidade, vendidos por unidade, pela aparência, sabor ou novidade, como o maracujá-doce, atualmente, em alguns centros consumidores.

Pelos resultados obtidos, considera-se que a agroindústria de sucos no Brasil deve estudar a hipótese de adquirir lotes de frutos roxos e rosados como parte de sua matéria-prima, a fim de elevar seu rendimento industrial.

Quanto à coloração da casca, 'Roxinho-Miúdo' apresentouse extremamente roxo, quase preto. 'Paulista' é roxo-avermelhado, com pintas brancas, e 'Maracujá-Maçã', rosado.

\section{CONCLUSÕES}

1. Os frutos de 'Roxinho-Miúdo' correspondem à preferência internacional, sendo apropriados para a exportação na forma de frutas frescas para consumo in natura.

2. Os frutos de 'Paulista' são ovais, de tamanho, forma e sabor mais adequados ao gosto do consumidor brasileiro. Podem ser comercializados como frutas frescas ou direcionados à agroindústria, para aumentar o rendimento industrial.

3. Os frutos do 'Maracujá-Maçã' são de coloração e formato diferenciado. Mostraram-se mais adequados ao nicho de mercado de frutas frescas de alta qualidade, onde as frutas são vendidas por unidade.

\section{AGRADECIMENTOS}

Os autores agradecem a contribuição de Valdemir Álvares, José Luiz Hernandes e Luís Carlos Pirassoli na manutenção do Banco de Germoplasma.

\section{REFERÊNCIAS}

ALEXANDER, M. P. A Versatile stain for pollen fungi, yeast and bactéria. Stain Tecnology, Baltimore, v. 55; p.13-18, 1980.

BERNACCI, L.C.; VITTA, F.A. \& BAKKER, Y.V. Passifloraceae. In WANDERLEY,M.GL.; SHEPPERD, G.J.; MELHEM, T.S.; GIULIETTI, A.M. \& M. KIRIZAWA (Eds.) Flora Fanerogâmica do Estado de São Paulo, São Paulo: RiMa/FAPESP, 2003, v. 3., p.247-274.

BROGLIA, M. \& BRUNORI, A Synergistic Effect of Low Temperature and High Sucrose Concentration on Maize Pollen Viability in Aqueus Medium. Crop Science, Madison, v.34, p.528-529, 1994.

DARLINGTON, C. D. \& LACOUR, L.F. The Handling of chromosomes, London: Ed. Darien Hafner, 1977. 272p.

FNP Consultoria \& Comércio. Agrianual 2002 - Anuário Estatístico da Agricultura Brasileira. Maracujá. São Paulo: Argos Comunicação. 2001.p. 402-408.

GUERRA, M. S. Introdução à Citogenética Geral. Rio de Janeiro: Guanabara Koogan. 1988. 142p.

INGLEZ DE SOUSA, J.S. \& MELETTI, L.M.M. Maracujá: espécies, variedades e cultivo. Piracicaba : FEALQ, 1997. 179p. (Biblioteca de Ciências Agrárias Luiz de Queiroz, 3).

LEVAN, A.; FREDGA, K.; SANDEBERG, A.A. Nomenclature for centromeric position on chromosomes. Hereditas, Lund, v 52, p. 201-220. 1964

McGILL, R.; TUKEY, J.W. \& LARSEN, W.A. Variations of box plots. The American Statistician, Alexandria, v. 32, p.12-16. 1978.

MEDINA, D.M. and CONAGIN, C.T.H.M. Técnica Citológica, Campinas: Instituto Agronômico, 1964. 108p. (Boletim Científico, 2610).

MELETTI, L.M.M. 'Maracujá-maçã'. In: DONADIO, L.C. Novas Variedades Brasileiras de Frutas. Sociedade Brasileira Fruticultura: Jaboticabal. 2000.p.154-155.

MELETTI, L.M.M. \& BRÜCKNER, C.H. Melhoramento Genético. In: BRÜCKNER, C.H. \& PICANÇO, M. C. Maracujá: tecnologia de produção, pós-colheita, agroindústria e mercado. Porto Alegre: Cinco Continentes, 2001. p. 345-385.

MELETTI, L.M.M. \& MAIA, M.L. Maracujá: Produção e Comercialização. Campinas: Instituto Agronômico, 1999. 62 p. (Boletim Técnico, 181).

MELETTI, L.M.M.; SOARES-SCOTT, M.D.; PINTO-MAGLIO, C.A.; MARTINS, F.P. Caracterização de germoplasma de maracujazeiro (Passiflora spp.). Revista Brasileira de Fruticultura, Cruz das Almas, v.14, n.2, p. 157-162, 1992.

MELETTI, L.M.M.; SOARES-SCOTT, M.D.; BERNACCI, L.C.; PINTOMAGLIO, C.A.; MARTINS, F.P. Caracterização agronômica e 
seleção de germoplasma de maracujá (Passiflora spp.). In: CONGRESSO BRASILEIRO FRUTICULTURA,13., 1994, Salvador.

Anais... Salvador: Sociedade Brasileira Fruticultura, v.3, p. 821-822.

TODA FRUTA. Boletim eletrônico. Jaboticabal: SBF - Sociedade Brasileira Fruticultura. edição on line de 28-02-2002. 4p.

OLIVEIRA, J.C. de; FERREIRA, F.R.; RUGGIERO, C.; NAKAMURA, K. Caracterização e avaliação de germoplasma de Passiflora edulis. In: CONGRESSO BRASILEIRO FRUTICULTURA,9., 1987, Campinas. Anais... Campinas: SBF, v.2, p. 591-596.

SOARES-SCOTT, M.D. Caracterização citogenética de algumas espécies e híbridos inter-específicos de Passiflora. 1998. 89f. Dissertação (Mestrado em Ciências Biológicas - Área de Biologia Celular), Universidade Estadual de Campinas, Campinas, 1998.

SOARES-SCOTT M.D.; MELETTI, L.M.M. AND RECCO-PIMENTEL S.M. Meiotic behaviour and pollen fertility in sexual and somatic hybrids of Passiflora species. Caryologia, Florence, Italy, v. 56, n. 1, p. 129-138, 2003.

SOUZA, A.C.G.de \& SANDI, D. Industrialização. BRÜCKNER, C.H. \& PICANÇO, M. C. Maracujá: tecnologia de produção, pós-colheita, agroindústria e mercado. Porto Alegre: Cinco Continentes, 2001. p. 305-344. 